\title{
System Characterization Report on Planet's SuperDove
}

Chapter F of

System Characterization of Earth Observation Sensors

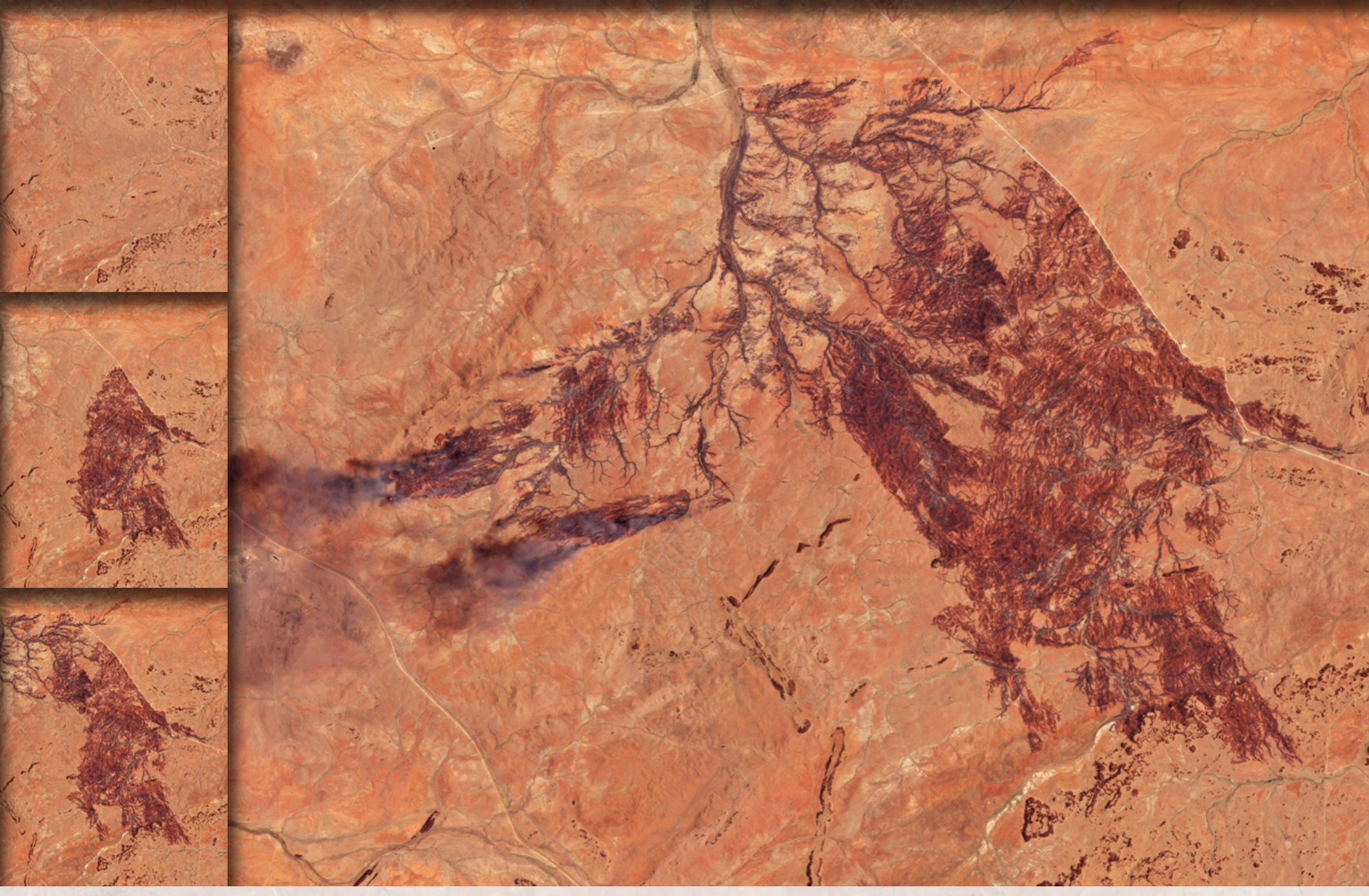

Open-File Report 2021-1030-F

U.S. Department of the Interior

U.S. Geological Survey 
Cover: Images captured by PlanetScope of Cooya Pooya, Australia, show the progression of bush fires on October 30, November 2, November 11 (left, top to bottom), and November 13, 2021 (right). Over the course of 2 weeks, the fires spread intermittently, leaving behind a dark burn scar. In the final image (captured on November 13), open flames are visible at the base of plumes of gray smoke. Images courtesy of Planet, licensed under the Creative Commons Attribution-NonCommercial 2.0 Generic license. 


\section{System Characterization Report on Planet's SuperDove}

By Minsu Kim, ${ }^{1}$ Seonkyung Park, ${ }^{1}$ Cody Anderson, ${ }^{2}$ and Gregory L. Stensaas ${ }^{2}$

Chapter F of

System Characterization of Earth Observation Sensors

Compiled by Shankar N. Ramaseri Chandra ${ }^{1}$

${ }^{1} \mathrm{KBR}$, Inc., under contract to the U.S. Geological Survey.

${ }^{2}$ U.S. Geological Survey.

Open-File Report 2021-1030-F 


\section{U.S. Geological Survey, Reston, Virginia: 2022}

For more information on the USGS - the Federal source for science about the Earth, its natural and living resources, natural hazards, and the environment—visit https://www.usgs.gov or call 1-888-ASK-USGS.

For an overview of USGS information products, including maps, imagery, and publications, visit https://store.usgs.gov/.

Any use of trade, firm, or product names is for descriptive purposes only and does not imply endorsement by the U.S. Government.

Although this information product, for the most part, is in the public domain, it also may contain copyrighted materials as noted in the text. Permission to reproduce copyrighted items must be secured from the copyright owner.

Suggested citation:

Kim, M., Park, S., Anderson, C., and Stensaas, G.L., 2022, System characterization report on Planet's SuperDove, chap. F of Ramaseri Chandra, S.N., comp., System characterization of Earth observation sensors: U.S. Geological Survey Open-File Report 2021-1030, 19 p., https://doi.org/10.3133/ofr20211030F.

ISSN 2331-1258 (online) 


\section{Contents}

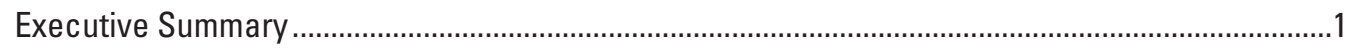

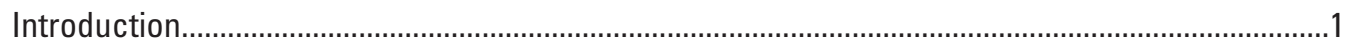

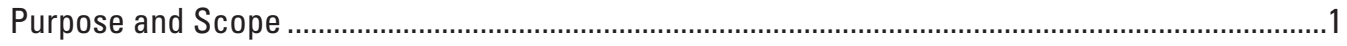

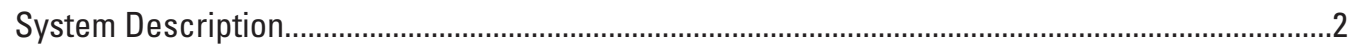

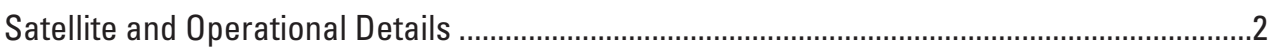

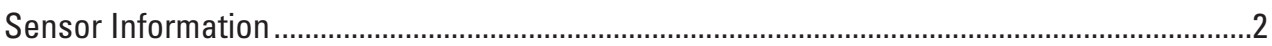

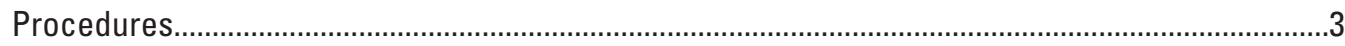

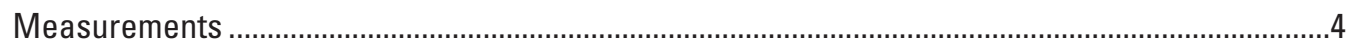

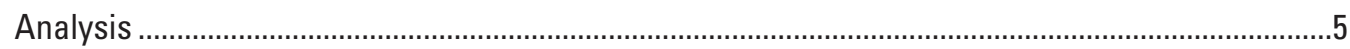

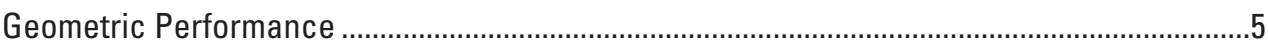

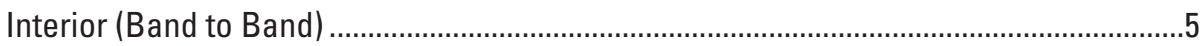

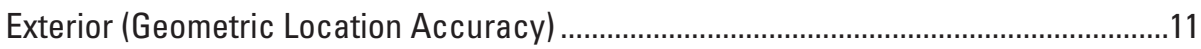

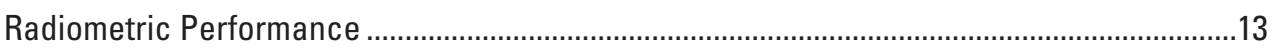

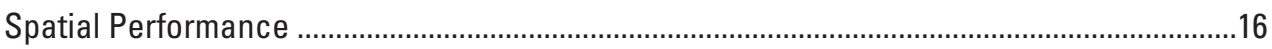

Summary and Conclusions .......................................................................................................

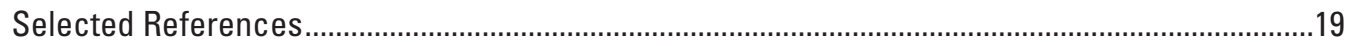

\section{Figures}

1. Graph showing Planet's SuperDove relative spectral response .........................................

2. Band 4 to band 2 geometric error map of Scottsdale, Arizona .............................................

3. Band 4 to band 2 geometric error histograms for easting and northing and error distribution of Scottsdale, Arizona......................................................................................

4. Band 4 to band 6 geometric error map of Scottsdale, Arizona...........................................8

5. Band 4 to band 6 geometric error histograms for easting and northing and error distribution of Scottsdale, Arizona...................................................................................

6. Band 4 to band 8 geometric error map of Scottsdale, Arizona..........................................10

7. Band 4 to band 8 geometric error histograms for easting and northing and error distribution of Scottsdale, Arizona....................................................................................11

8. Relative geometric error map for Sentinel-2 and Planet's SuperDove 2257 of Scottsdale, Arizona

9. Relative geometric error histograms for easting and northing and error distribution for Sentinel-2 and Planet's SuperDove 2257 of Scottsdale, Arizona ............13

10. Graphs showing Top of Atmosphere reflectance comparison for Sentinel-2 and Planet's SuperDove 2271 of Scottsdale, Arizona ............................................................15

11. SuperDove image of calibration site at Baotou, China ................................................17

12. Graphs showing band 2 raw edge transects and shifted transects ..............................17

13. Graphs showing band 2 edge spread function and line spread function and modulation transfer function 


\section{Tables}

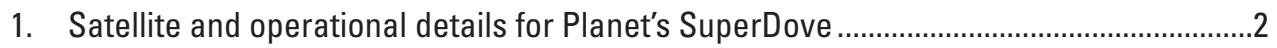

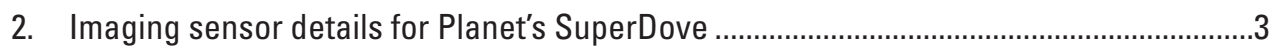

3. U.S. Geological Survey measurement results ………......................................................

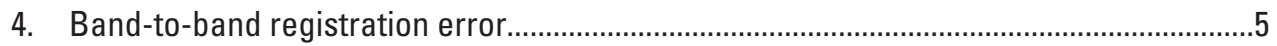

5. Geometric error of Planet's SuperDove relative to Sentinel-2 imagery ...........................12

6. Top of Atmosphere reflectance comparison for Sentinel-2 images against

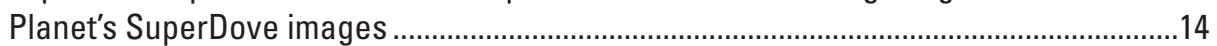

7. Spatial performance of Planet's SuperDove …………................................................16

\section{Conversion Factors}

International System of Units to U.S. customary units

\begin{tabular}{|c|c|c|}
\hline Multiply & By & To obtain \\
\hline \multicolumn{3}{|c|}{ Length } \\
\hline centimeter $(\mathrm{cm})$ & 0.3937 & inch (in.) \\
\hline meter $(\mathrm{m})$ & 3.281 & foot $(\mathrm{ft})$ \\
\hline meter $(\mathrm{m})$ & 1.094 & yard (yd) \\
\hline kilometer (km) & 0.6214 & mile (mi) \\
\hline \multicolumn{3}{|c|}{ Mass } \\
\hline kilogram (kg) & 2.205 & pound avoirdupois (lb) \\
\hline
\end{tabular}

U.S. customary units to International System of Units

\begin{tabular}{rcc}
\hline Multiply & By & To obtain \\
\hline & Mass & \\
\hline pound, avoirdupois $(\mathrm{lb})$ & 0.4536 & kilogram $(\mathrm{kg})$ \\
\hline
\end{tabular}

\section{Abbreviations}

ECCOE Earth Resources Observation and Science Cal/Val Center of Excellence

JACIE Joint Agency Commercial Imagery Evaluation

USGS U.S. Geological Survey 


\title{
System Characterization Report on Planet's SuperDove
}

\author{
By Minsu Kim, ${ }^{1}$ Seonkyung Park, ${ }^{1}$ Cody Anderson, ${ }^{2}$ and Gregory L. Stensaas ${ }^{2}$
}

\section{Executive Summary}

This report addresses system characterization of Planet's SuperDove and is part of a series of system characterization reports produced and delivered by the U.S. Geological Survey Earth Resources Observation and Science Cal/Val Center of Excellence. These reports present and detail the methodology and procedures for characterization; present technical and operational information about the specific sensing system being evaluated; and provide a summary of test measurements, data retention practices, data analysis results, and conclusions.

Since 2013, Planet has launched more than 360 Dove 3U CubeSats, where U stands for 10-centimeter $(\mathrm{cm}) \times 10-\mathrm{cm} \mathrm{x}$ 10-cm stowed dimensions, each weighing about 5.8 kilograms. Since 2015, all Dove satellites have had four-band imagers with about a 3-meter (m) pixel ground sample distance. Since 2016, all Doves have been launched into Sun-synchronous orbits varying from 474 to 524 kilometers, with inclinations between 97 and 98 degrees. The Dove series satellites do not have orbit maintenance capabilities; thus, their orbits decay slowly over time, contributing to shorter lifetimes of about 3 years. More information on Planet satellites and sensors is available in the " 2020 Joint Agency Commercial Imagery Evaluation-Remote Sensing Satellite Compendium” and from the manufacturer at https://www.planet.com/.

The Earth Resources Observation and Science Cal/Val Center of Excellence system characterization team completed data analyses to characterize the geometric (interior and exterior), radiometric, and spatial performances. Results of these analyses indicate that SuperDove has a band-to-band geometric performance in the range of $-1.701 \mathrm{~m}(-0.567$ pixel $)$ to $1.173 \mathrm{~m}(0.391$ pixel $)$ in easting and $-4.950 \mathrm{~m}$ ( -1.650 pixels $)$ to $6.051 \mathrm{~m}$ (2.017 pixels) in northing, an image-to-image geometric performance of $-1.17 \mathrm{~m}(-0.39$ pixel $)$ to $23.45 \mathrm{~m}$ (7.82 pixels) in easting and $-10.61 \mathrm{~m}(-3.54$ pixels) to $-4.43 \mathrm{~m}$ ( -1.48 pixels) in northing offset in comparison to Sentinel-2, a radiometric performance in the range of -0.043 to 0.020 in offset and 0.812 to 1.246 in slope, and a spatial performance in the range of 3.59 to 3.70 pixels for full width at half maximum, with a modulation transfer function at a Nyquist frequency in the range of 0.005 to 0.008 .

${ }^{1} \mathrm{KBR}$, Inc., under contract to the U.S. Geological Survey.

${ }^{2}$ U.S. Geological Survey.

\section{Introduction}

Planet is well known for launching reduced-mass Earth observation satellites, with its Dove satellites weighing 5.8 kilograms. Each Dove is a $3 \mathrm{U}$ CubeSat, where U stands for 10 -centimeter $(\mathrm{cm}) \times 10-\mathrm{cm} \times 10-\mathrm{cm}$ stowed dimensions. The first prototype Doves were launched in April 2013, followed by at least 20 more successful launches in the 7 years since, each carrying a flock of multiple Dove satellites, for a total of more than 360 Dove satellites launched into orbit. Planet has used this frequent launch cadence to produce at least 17 builds, or generations, of Doves with various technological and operating improvements in each build, which has resulted in continual advancement in capability in the 7 years since the launch of the first Dove. All data are provided with permission from Planet through their standard data access portal.

The data analysis results provided in this report have been derived from approved Joint Agency Commercial Imagery Evaluation (JACIE) processes and procedures. JACIE was formed to leverage resources from several Federal agencies for the characterization of remote sensing data and to share those results across the remote sensing community. More information about JACIE is available at https://www.usgs.gov/corescience-systems/eros/calval/jacie?qt-science_support_page related_con $=3 \#$ qt-science_support_page_related_con.

\section{Purpose and Scope}

The purpose of this report is to describe the specific sensor or sensing system, test its performance in three categories, complete related data analyses to quantify these performances, and report the results in a standardized document. In this chapter, the SuperDove sensor is described. The performance testing of the system is limited to geometric, radiometric, and spatial. The scope of the geometric assessment is limited to testing the interior alignments of spectral bands against each other, and the exterior alignment is tested in reference to Sentinel-2.

The U.S. Geological Survey (USGS) Earth Resources Observation and Science Cal/Val Center of Excellence (ECCOE) project, and the associated system characterization process used for this assessment, follows the USGS Fundamental Science Practices, which include maintaining 
data, information, and documentation needed to reproduce and validate the scientific analysis documented in this report. Additional information and guidance about Fundamental Science Practices and related resource information of interest to the public are available at https://www.usgs.gov/ about/organization/science-support/office-science-qualityand-integrity/fundamental-science-practices. For additional information related to the report, please contact ECCOE at eccoe@usgs.gov.

\section{System Description}

This section describes the satellite and operational details and provides information about Planet's SuperDove sensor.

\section{Satellite and Operational Details}

The satellite and operational details for Planet's SuperDove are listed in table 1.

\section{Sensor Information}

The imaging sensor details for Planet's SuperDove are listed in table 2. The relative spectral responses for Planet's SuperDove are shown in figure 1.

Table 1. Satellite and operational details for Planet's SuperDove.

[cm, centimeter; NIR, near infrared; $\mathrm{km}$, kilometer; ${ }^{\circ}$, degree; \pm , plus or minus; lat., latitude; $\mathrm{m}$, meter; $<$, less than]

\begin{tabular}{|c|c|}
\hline Product information & SuperDove \\
\hline \multicolumn{2}{|c|}{ Satellite and operational information } \\
\hline Product name & Level 3B \\
\hline Satellite name & Planet's SuperDove \\
\hline Satellite size & CubeSat $3 U$ form factor $(10 \mathrm{~cm} \times 10 \mathrm{~cm} \times 30 \mathrm{~cm})$ \\
\hline Sensor name(s) & Planetscope \\
\hline Sensor type & Multispectral (blue, green, red, NIR) \\
\hline Mission type & Global land-monitoring mission \\
\hline Launch date & Multiple dates, beginning November 2018 \\
\hline Number of satellites & 130 Planetscope satellites within constellation \\
\hline Expected lifetime & About 6 years \\
\hline Operator & Planet \\
\hline \multicolumn{2}{|c|}{ Operational details } \\
\hline Operating orbit & Sun-synchronous orbit \\
\hline Orbital altitude range & $475 \mathrm{~km}$ \\
\hline Sensor angle altitude & $98.0^{\circ}$ inclination \\
\hline Imaging time & Variable \\
\hline Geographic coverage & Land imaging $\pm 81.5^{\circ}$ lat. \\
\hline Temporal resolution & Daily \\
\hline Temporal coverage & 2018 to present \\
\hline Imaging angles & $\pm 25^{\circ}$ \\
\hline Ground sample distance(s) & $3 \mathrm{~m}$ \\
\hline Data licensing & Restricted \\
\hline Data pricing & Limited free data; commercial imagery pricing \\
\hline Data latency & $<24$ hours \\
\hline Product abstract & https://www.planet.com/products/planet-imagery/ \\
\hline Product locator & https://www.planet.com/products/ \\
\hline
\end{tabular}


Table 2. Imaging sensor details for Planet's SuperDove.

[ $\mu \mathrm{m}$, micrometer; $\mathrm{m}$, meter; NIR, near infrared]

\begin{tabular}{lcccc}
\hline \multirow{2}{*}{ Spectral band details } & \multicolumn{3}{c}{ SuperDove } \\
\cline { 2 - 5 } & $\begin{array}{c}\text { Lower band } \\
(\boldsymbol{\mu m})\end{array}$ & $\begin{array}{c}\text { Upper band } \\
(\boldsymbol{\mu \mathbf { m } )}\end{array}$ & $\begin{array}{c}\text { Radiometric resolution } \\
(\mathbf{b i t s})\end{array}$ & $\begin{array}{c}\text { Ground sample distance } \\
(\mathbf{m})\end{array}$ \\
\hline Band 1 -coastal blue & 0.431 & 0.452 & 12 (scaled to 16) & 3 \\
Band 2-blue & 0.465 & 0.515 & 12 (scaled to 16) & 3 \\
Band 3-green I & 0.513 & 0.549 & 12 (scaled to 16) & 3 \\
Band 4-green II & 0.547 & 0.583 & 12 (scaled to 16) & 3 \\
Band 5-yellow & 0.600 & 0.620 & 12 (scaled to 16) & 3 \\
Band 6-red & 0.650 & 0.682 & 12 (scaled to 16) & 3 \\
Band 7-red edge & 0.697 & 0.713 & 12 (scaled to 16) & 3 \\
Band 8-NIR & 0.845 & 0.885 & 12 (scaled to 16) & 3 \\
\hline
\end{tabular}

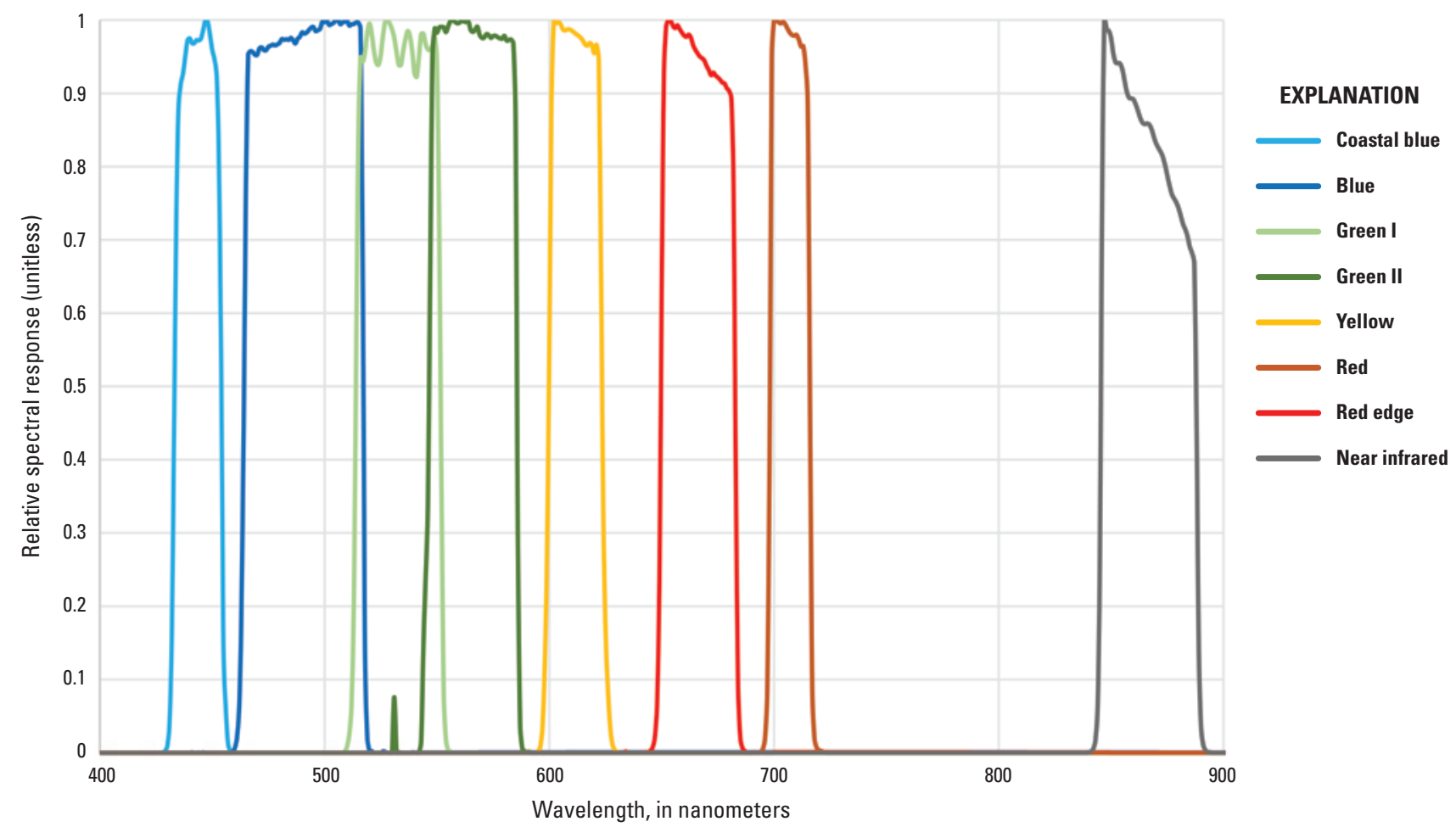

Figure 1. Planet's SuperDove relative spectral response.

\section{Procedures}

ECCOE has established standard processes to identify Earth observing systems of interest and to assess the geometric, radiometric, and spatial qualities of data products from these systems.

The assessment steps are as follows:

- system identification and investigation to learn the general specifications of the satellite and its sensor(s);
- data receipt and initial inspection to understand the characteristics and any overt flaws in the data product so that it may be further analyzed;

- geometry characterization, including interior geometric orientation measuring the relative alignment of spectral bands and exterior geometric orientation measuring how well the georeferenced pixels within the image are aligned to a known reference; 
- radiometry characterization, including assessing how well the data product correlates with a known reference and, when possible, assessing the signal-to-noise ratio; and

- spatial characterization, assessing the two-dimensional fidelity of the image pixels to their projected ground sample distance.

Data analysis and test results are maintained at the USGS Earth Resources Observation and Science Center by the ECCOE project.

\section{Measurements}

The observed USGS measurements are listed in table 3. Details about the methodologies used are outlined in the "Analysis" section.

Table 3. U.S. Geological Survey measurement results.

[m, meter; RMSE, root mean square error; NIR, near infrared; FWHM, full width at half maximum; RER, relative edge response; MTF, modulation transfer function; USGS, U.S. Geological Survey]

\begin{tabular}{|c|c|}
\hline Description of product & Top of Atmosphere reflectance \\
\hline \multicolumn{2}{|c|}{ Geometric performance (easting, northing), in meters (pixels) } \\
\hline Interior (band to band) & $\begin{array}{l}\text { All bands combined to reference band } 4 \text { (green II) } \\
\text { Mean: }-1.701 \text { to } 1.173 \mathrm{~m}(-0.567 \text { to } 0.391),-4.950 \text { to } 6.051 \mathrm{~m}(-1.650 \text { to } 2.017) \\
\text { RMSE: } 0.444 \text { to } 2.361 \mathrm{~m}(0.148 \text { to } 0.787), 0.672 \text { to } 6.099 \mathrm{~m}(0.224 \text { to } 2.033)\end{array}$ \\
\hline Exterior (geometric location accuracy) & $\begin{array}{l}\text { Mean: }-1.17 \text { to } 23.45 \mathrm{~m}(-0.39 \text { to } 7.82),-10.61 \text { to }-4.43 \mathrm{~m}(-3.54 \text { to }-1.48) \\
\text { RMSE: } 1.55 \text { to } 2.75 \mathrm{~m}(0.52 \text { to } 0.92), 4.87 \text { to } 10.83 \mathrm{~m}(1.62 \text { to } 3.61)\end{array}$ \\
\hline $\begin{array}{l}\text { Radiometric evaluation (linear regression- } \\
\text { SuperDove versus Sentinel-2 reflectance) }\end{array}$ & $\begin{array}{l}\text { Band } 1-\text { coastal blue (offset, slope): }(0.005 \text { to } 0.020,0.812 \text { to } 0.890) \\
\text { Band } 2-\text { blue (offset, slope): }(-0.043 \text { to }-0.027,1.119 \text { to } 1.246) \\
\text { Band } 4-\text { green II (offset, slope): }(-0.032 \text { to }-0.018,1.076 \text { to } 1.205) \\
\text { Band 6-red (offset, slope): }(-0.028 \text { to }-0.021,1.086 \text { to } 1.193) \\
\text { Band 7-red edge (offset, slope): }(-0.020 \text { to }-0.020,1.060 \text { to } 1.099) \\
\text { Band } 8-\text {-NIR (offset, slope): }(-0.011 \text { to } 0.005,0.977 \text { to } 1.021)\end{array}$ \\
\hline \multicolumn{2}{|r|}{ Known artifacts and quality issues } \\
\hline USGS noted artifacts/quality issues & $\begin{array}{l}\text { As predicted by the large line spread function (FWHM of } 2.6 \text { pixels or greater), the } \\
\text { SuperDove imagery does not have precise transition across a target edge. }\end{array}$ \\
\hline
\end{tabular}




\section{Analysis}

This section of the report describes the geometric, radiometric, and spatial performance of Planet's SuperDove.

\section{Geometric Performance}

The geometric performance for Planet's SuperDove is characterized in terms of the interior (band-to-band alignment) and exterior (geometric location accuracy) geometric analysis results.

\section{Interior (Band to Band)}

For this analysis, each band of the SuperDove imagery was registered against band 4 (green II). Results from two separate images (represented in pixels) were gathered, as listed in table 4. Geometric error maps for each band combination from the SuperDove 2257 image, as well as the corresponding histogram graphs, are shown in figures $2-7$, where the red arrow represents an error vector with an easting and northing component and the yellow line is the grid. The geometric error maps indicate the directional shift and relative magnitude of the shift, and the histogram graphs indicate the frequency of observed mean error measurements within the image.

Table 4. Band-to-band registration error (in pixels).

[ID, identifier; RMSE, root mean square error]

\begin{tabular}{|c|c|c|c|c|c|}
\hline Scene ID & Band combination & $\begin{array}{l}\text { Mean error } \\
\text { (easting) }\end{array}$ & $\begin{array}{l}\text { Mean error } \\
\text { (northing) }\end{array}$ & $\begin{array}{c}\text { RMSE } \\
\text { (easting) }\end{array}$ & $\begin{array}{c}\text { RMSE } \\
\text { (northing) }\end{array}$ \\
\hline \multirow{4}{*}{$\begin{array}{l}\text { 20200109_164921_56_2271_3B } \\
\text { (SuperDove 2271, Roswell, New Mexico) }\end{array}$} & Band 4-band 1 & -0.524 & -0.353 & 0.787 & 0.854 \\
\hline & Band 4-band 3 & 0.014 & -0.004 & 0.148 & 0.250 \\
\hline & Band 4-band 5 & -0.535 & 1.530 & 0.585 & 1.597 \\
\hline & Band 4-band 8 & -0.567 & 1.062 & 0.733 & 1.219 \\
\hline \multirow{4}{*}{$\begin{array}{l}\text { 20200113_171859_39_2257_3B } \\
\quad \text { (SuperDove 2257, Scottsdale, Arizona) }\end{array}$} & Band 4-band 1 & 0.391 & -1.650 & 0.520 & 1.708 \\
\hline & Band 4-band 2 & -0.004 & -0.056 & 0.195 & 0.418 \\
\hline & Band 4-band 3 & 0.027 & -0.077 & 0.161 & 0.224 \\
\hline & Band 4-band 8 & -0.081 & -0.400 & 0.468 & 0.699 \\
\hline
\end{tabular}




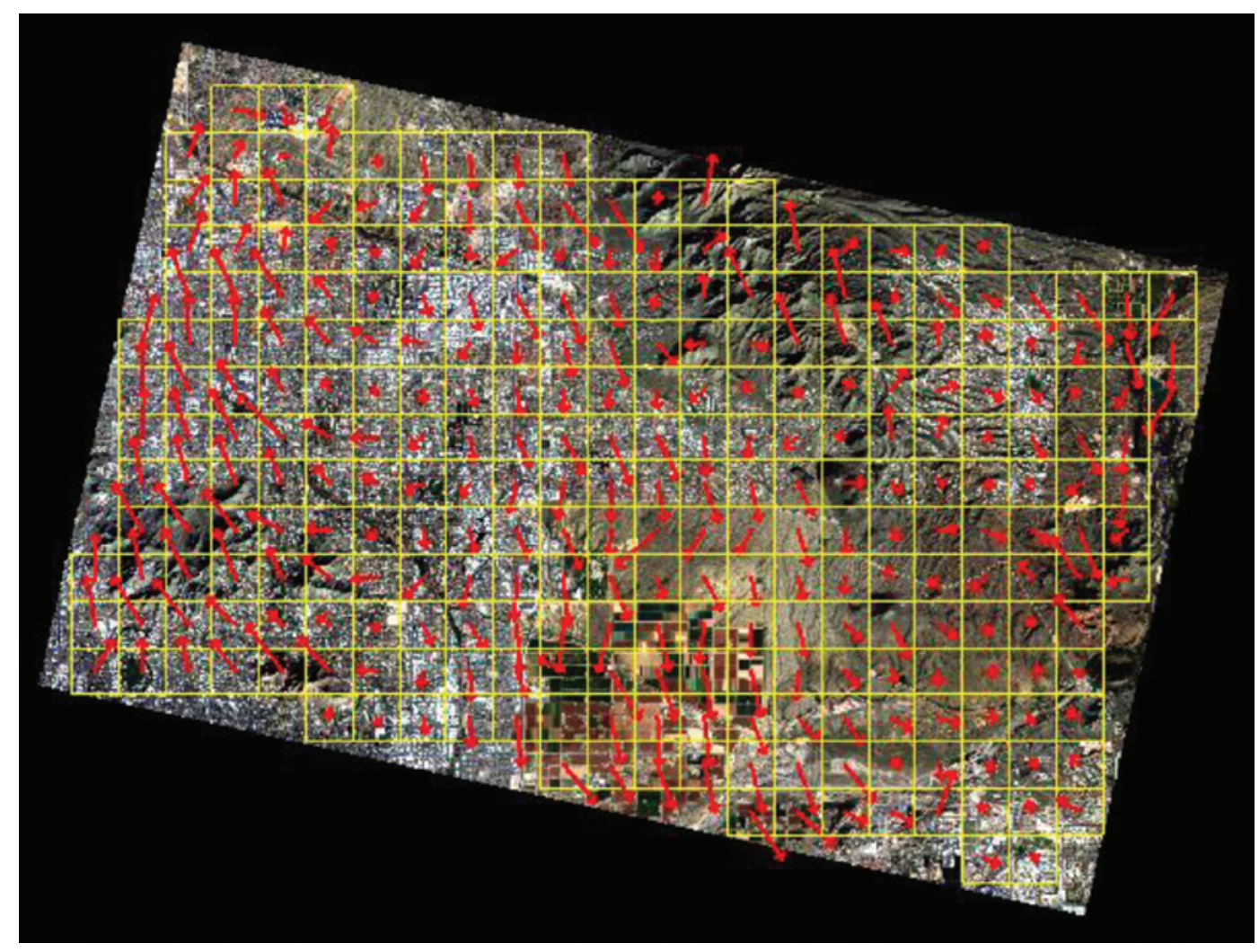

EXPLANATION

$\longrightarrow$ Easting and northing error

Grid

Figure 2. Band 4 (green II) to band 2 (blue) geometric error map of Scottsdale, Arizona. 

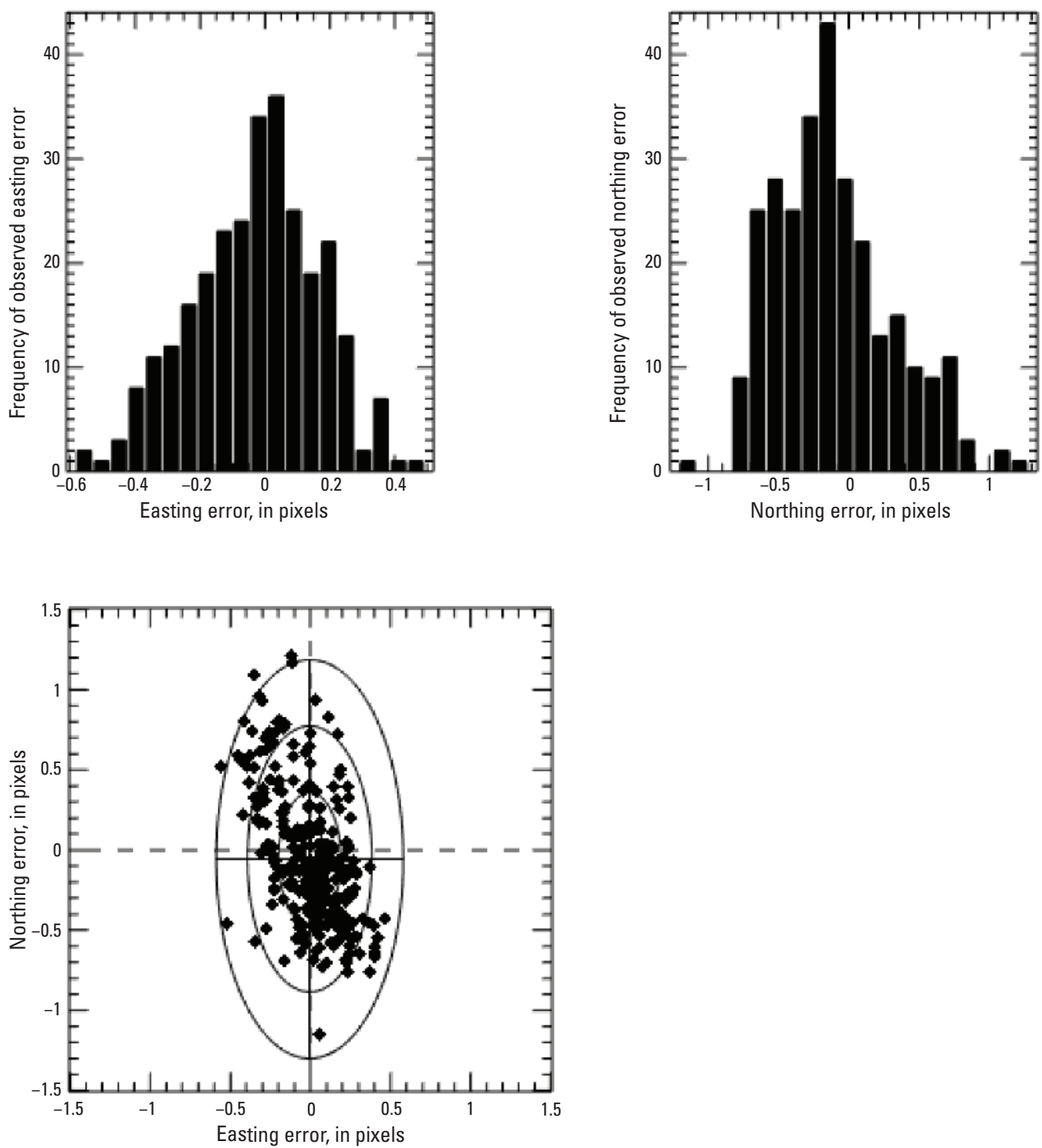

Figure 3. Band 4 (green II) to band 2 (blue) geometric error histograms for easting and northing (upper) and error distribution (lower) of Scottsdale, Arizona. 


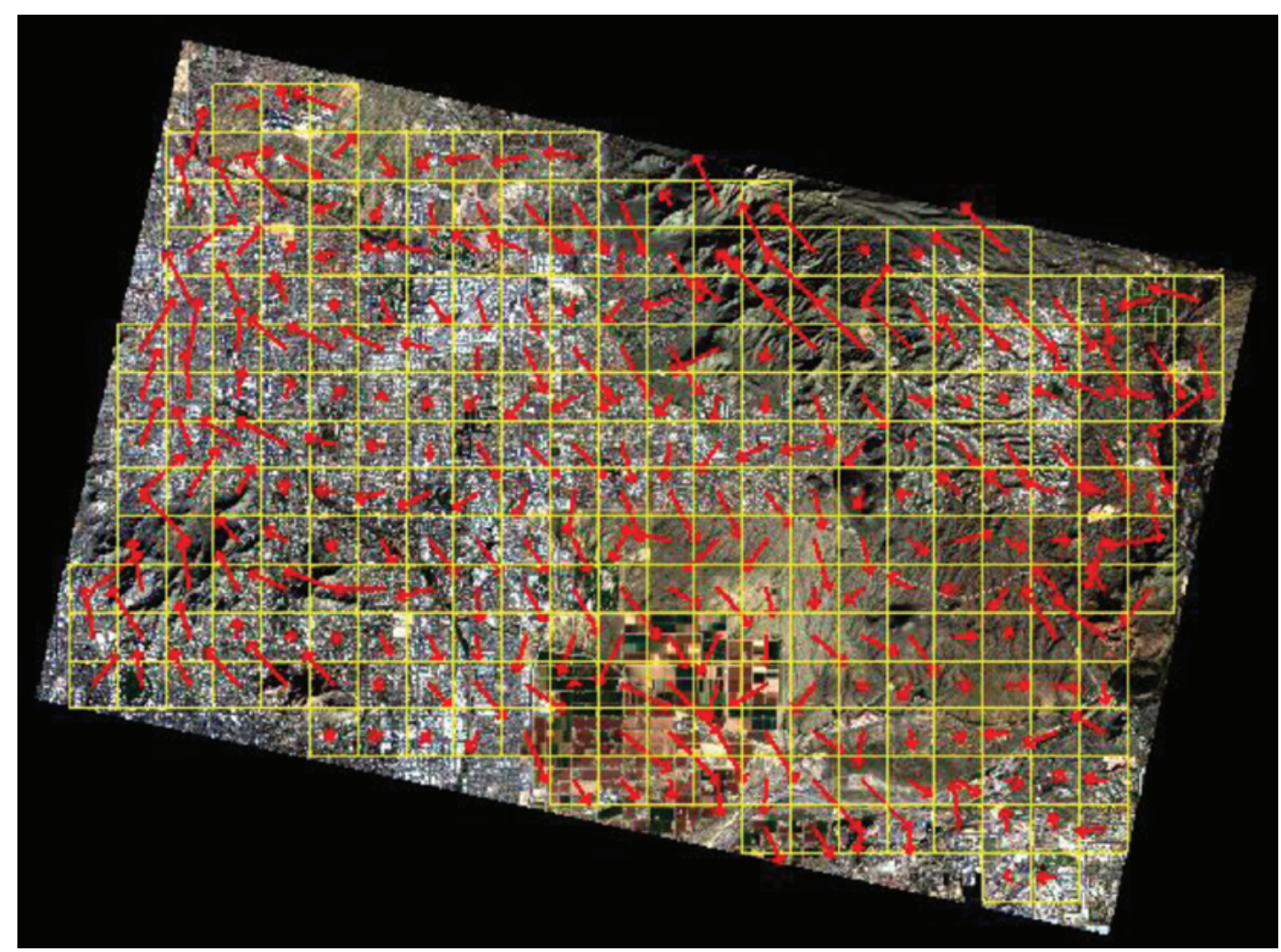

EXPLANATION

$\longrightarrow$ Easting and northing error

Grid

Figure 4. Band 4 (green II) to band 6 (red) geometric error map of Scottsdale, Arizona. 

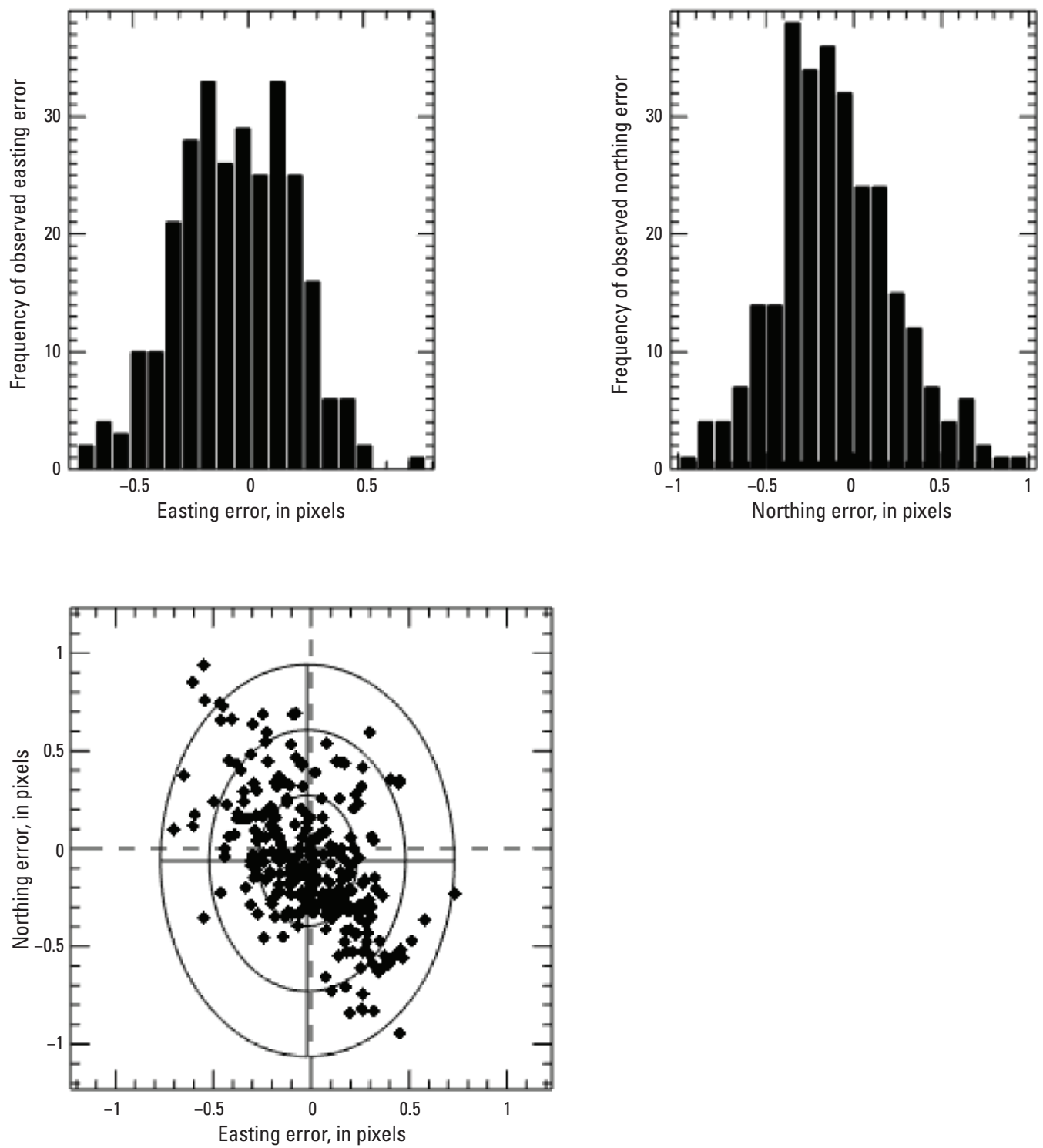

Figure 5. Band 4 (green II) to band 6 (red) geometric error histograms for easting and northing (upper) and error distribution (lower) of Scottsdale, Arizona. 


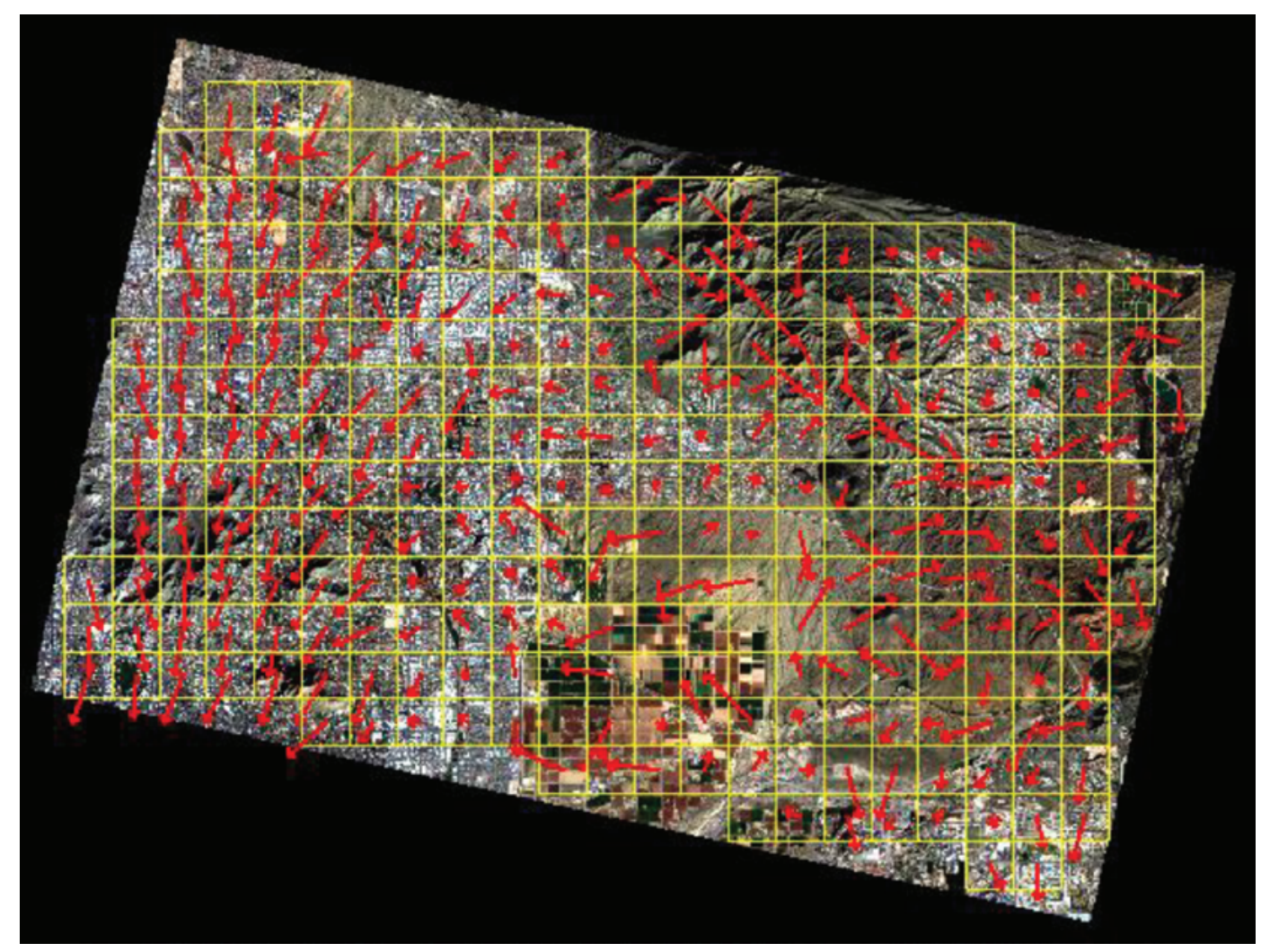

EXPLANATION

$\longrightarrow$ Easting and northing error

Grid

Figure 6. Band 4 (green II) to band 8 (near infrared) geometric error map of Scottsdale, Arizona. 

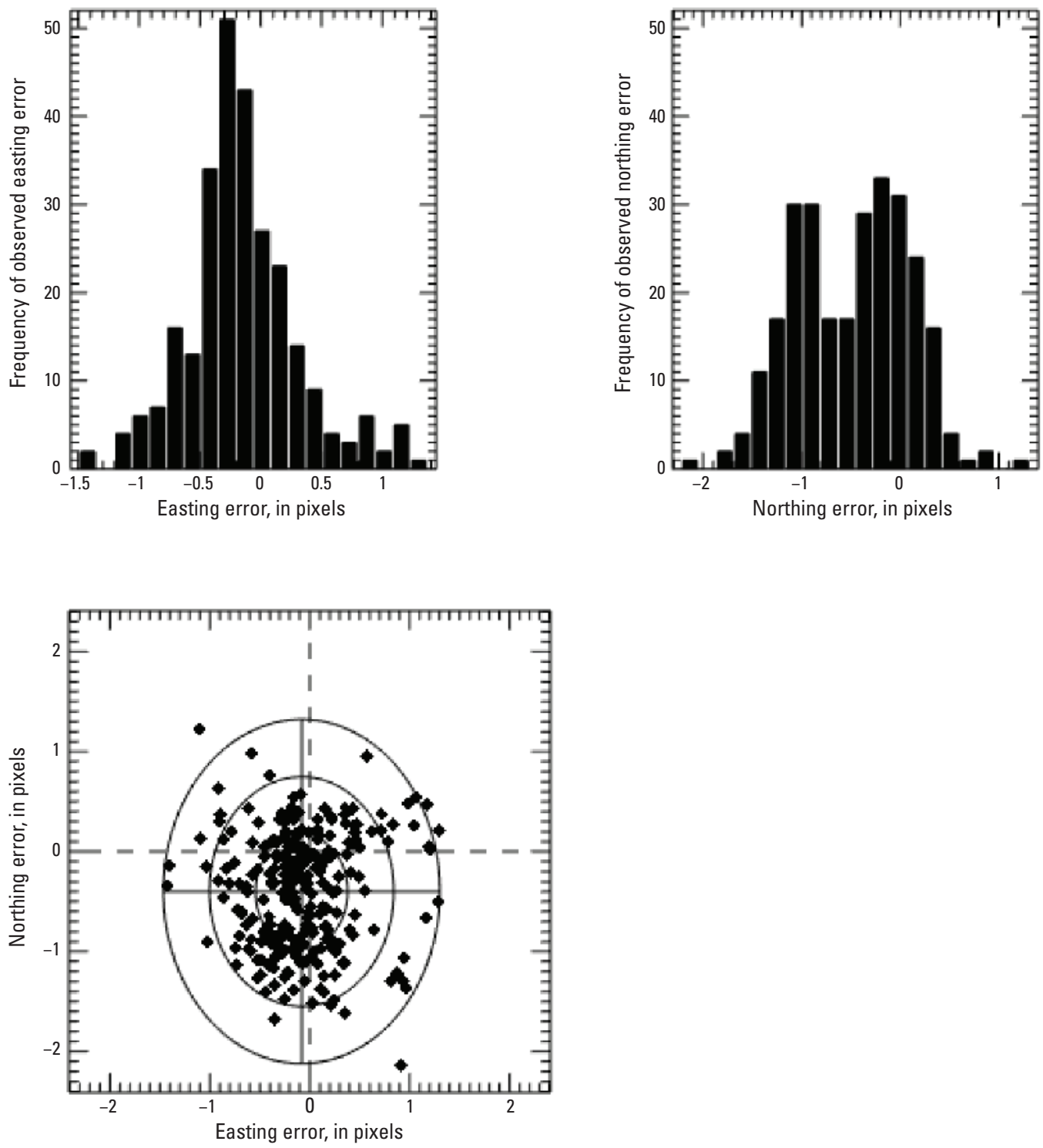

Figure 7. Band 4 (green II) to band 8 (near infrared) geometric error histograms for easting and northing (upper) and error distribution (lower) of Scottsdale, Arizona.

\section{Exterior (Geometric Location Accuracy)}

For this analysis, band 4 (green II) of the SuperDove images was compared against the corresponding band from three Sentinel-2 images over sites in Roswell, New Mexico, and Scottsdale, Arizona. Conjugate points in the reference and search images were identified automatically and refined using similarity measures such as normalized cross-correlation metrics, and the mean error and root mean square error results are listed in table 5, in pixels at a 10-meter ground sample distance. For each of the three images, geometric error maps showing the directional shift and relative magnitude of the shift, when compared with Sentinel-2, are provided in figures 8 and 9 . The Sentinel-2 imagery had a control uncertainty of about 3.6 meters. 
Table 5. Geometric error of Planet's SuperDove relative to Sentinel-2 imagery.

[ID, identifier; RMSE, root mean square error; $m$, meter]

\begin{tabular}{lcccc}
\hline \multicolumn{1}{c}{ Scene ID } & $\begin{array}{c}\text { Mean error } \\
\text { (easting) }\end{array}$ & $\begin{array}{c}\text { Mean error } \\
\text { (northing) }\end{array}$ & $\begin{array}{c}\text { RMSE } \\
\text { (easting) }\end{array}$ & $\begin{array}{c}\text { RMSE } \\
\text { (northing) }\end{array}$ \\
\hline S2B_MSIL1C_20200109T174719_N0208_R098_ & 7.82 pixels & -3.54 pixels & 0.92 pixel & 3.61 pixels \\
T13SES_20200109T194154 & $(23.45 \mathrm{~m})$ & $(-10.61 \mathrm{~m})$ & $(2.75 \mathrm{~m})$ & $(10.83 \mathrm{~m})$ \\
20200109_164921_56_2271_3B_AnalyticMS_TOAR & & & & \\
(SuperDove2271, Roswell, New Mexico) & & & & 1.62 pixels \\
S2A_MSIL1C_20200113T181711_N0208_R084_- & -0.39 pixel & -1.48 pixels & 0.52 pixel & $(4.87 \mathrm{~m})$ \\
T12SVC_20200113T195917 & $(-1.17 \mathrm{~m})$ & $(-4.43 \mathrm{~m})$ & $(1.55 \mathrm{~m})$ & \\
20200113_171859_39_2257_3B_AnalyticMS_TOAR & & & & \\
(SuperDove 2257, Scottsdale, Arizona) & & & & \\
\hline
\end{tabular}

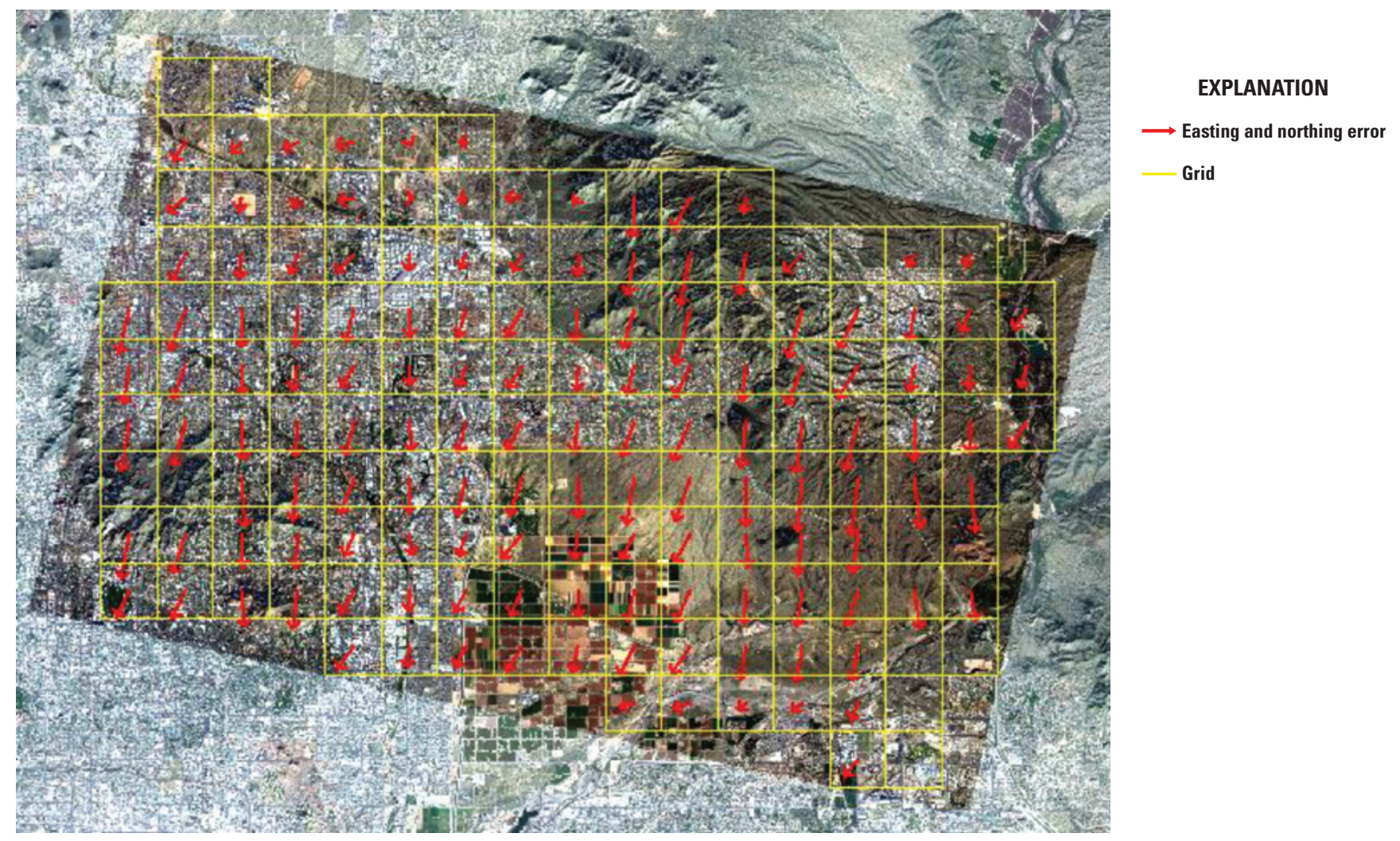

Figure 8. Relative geometric error map for Sentinel-2 and Planet's SuperDove 2257 of Scottsdale, Arizona. 

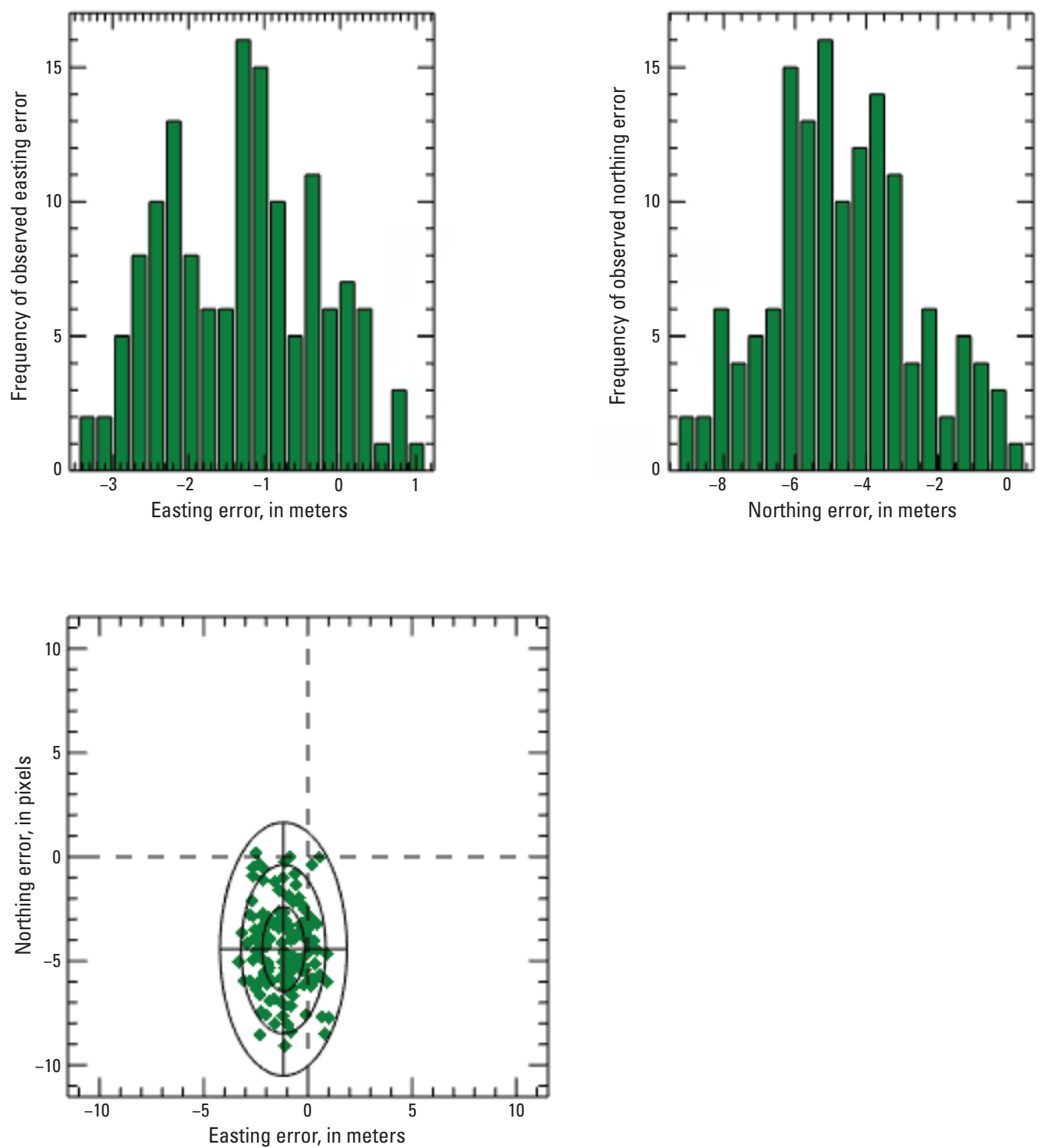

Figure 9. Relative geometric error histograms for easting and northing (upper) and error distribution (lower) for Sentinel-2 and Planet's SuperDove 2257 of Scottsdale, Arizona.

\section{Radiometric Performance}

For this analysis, cloud-free regions of interest were selected within two near-coincident SuperDove and Sentinel-2 scene pairs (table 6). Once the relative georeferencing error has been corrected, Top of Atmosphere reflectance values from the two sensors are extracted. The scatterplots in figure 10 are drawn in a way that the $\mathrm{x}$-axis is the reference sensor and the $\mathrm{y}$-axis is the comparison sensor. The linear regression, thus, represents Top of Atmosphere reflectance relative to that of the reference sensor. Ideally, the slope should be near unity, and the offset should be near zero. For instance, if the slope is greater than unity, that means the comparison sensor has a tendency to overestimate Top of Atmosphere reflectance compared to the reference sensor. Top of Atmosphere reflectance comparison results are listed in table 6. A band-by-band graphical comparison between the SuperDove image and the corresponding Sentinel-2 band is shown in figure 10. 


\section{System Characterization Report on Planet's SuperDove}

Table 6. Top of Atmosphere reflectance comparison for Sentinel-2 images against Planet's SuperDove images.

[ID, identifier; NIR, near infrared; \%, percent; $R^{2}$, coefficient of determination]

\begin{tabular}{|c|c|c|c|c|c|c|c|}
\hline Scene ID & Statistics & $\begin{array}{c}\text { Band } 1 \\
\text { (coastal } \\
\text { blue) }\end{array}$ & $\begin{array}{c}\text { Band } 2 \\
\text { (blue) }\end{array}$ & $\begin{array}{c}\text { Band } 4 \\
\text { (green II) }\end{array}$ & $\begin{array}{c}\text { Band } 6 \\
\text { (red) }\end{array}$ & $\begin{array}{c}\text { Band } 7 \\
\text { (red edge) }\end{array}$ & $\begin{array}{c}\text { Band } 8 \\
\text { (NIR) }\end{array}$ \\
\hline \multirow{2}{*}{$\begin{array}{l}\text { S2B_MSIL1C_20200109T174719_N0208_ } \\
\text { R098_T13SES_20200109T194154 } \\
\text { 20200109_164921_56_2271_3B_- } \\
\text { AnalyticMS_TOAR } \\
\text { (SuperDove 2271, Roswell, New } \\
\text { Mexico) }\end{array}$} & $R^{2}$ & 0.744 & 0.948 & 0.953 & 0.965 & 0.950 & 0.931 \\
\hline & Radical offset & 0.005 & -0.027 & -0.018 & -0.021 & -0.020 & -0.011 \\
\hline \multirow{4}{*}{$\begin{array}{l}\text { S2A_MSIL1C_20200113T181711_N0208_ } \\
\text { R084_T12SVC_20200113T195917 } \\
\text { 20200113_171859_39_2257_3B_- } \\
\text { AnalyticMS_TOAR } \\
\text { (SuperDove 2257, Scottsdale, Arizona) }\end{array}$} & Uncertainty (\%) & 5.70 & 8.01 & 9.61 & 11.39 & 9.36 & 10.88 \\
\hline & $R^{2}$ & 0.636 & 0.920 & 0.917 & 0.930 & 0.892 & 0.803 \\
\hline & Radical offset & 0.020 & -0.043 & -0.032 & -0.028 & -0.020 & 0.005 \\
\hline & Radical slope & 0.812 & 1.246 & 1.205 & 1.193 & 1.099 & 0.977 \\
\hline
\end{tabular}


Coastal blue
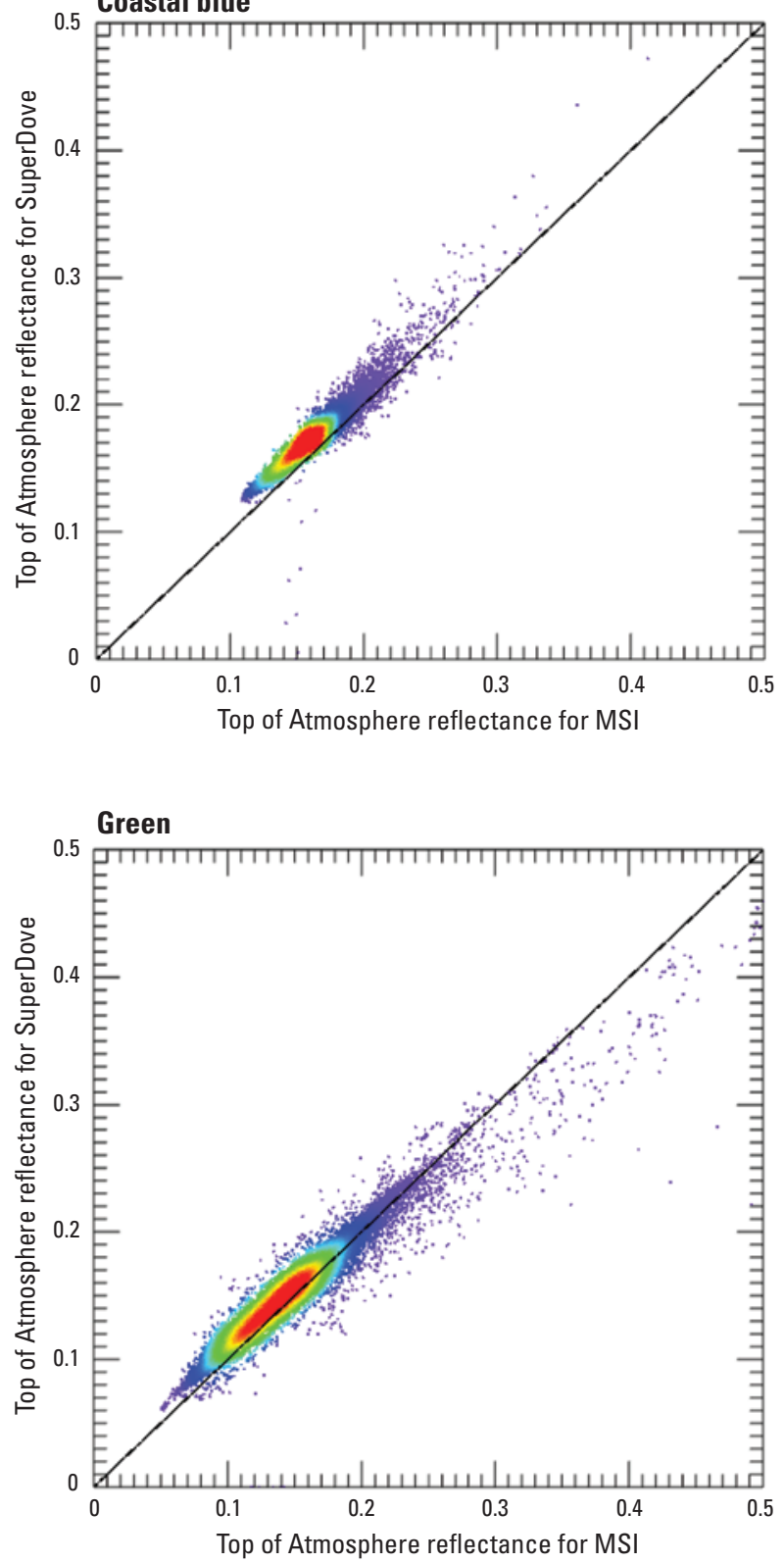
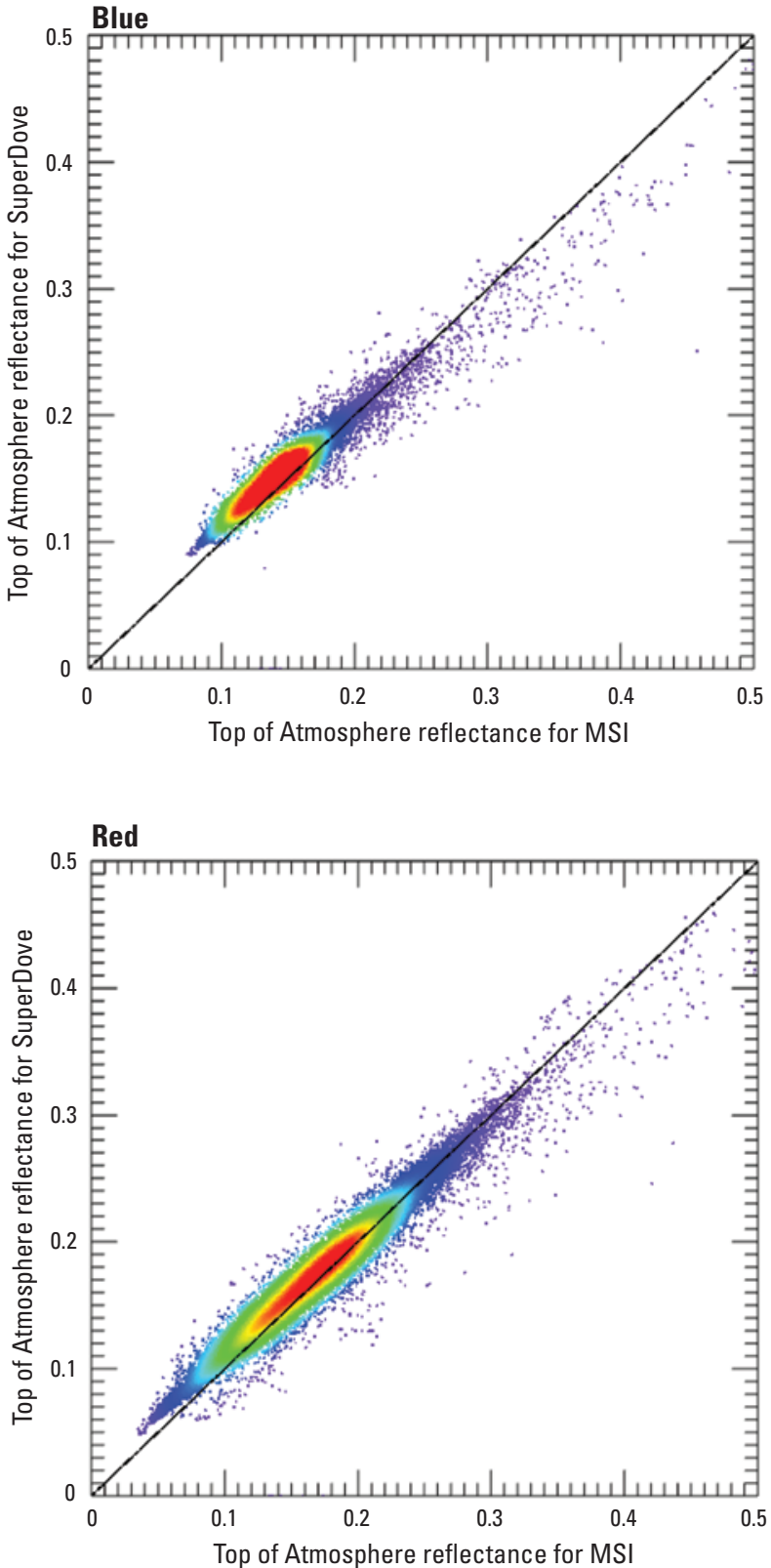

Figure 10. Top of Atmosphere reflectance comparison for Sentinel-2 and Planet's SuperDove 2271 of Scottsdale, Arizona. [MSI, Sentinel-2 Multispectral Instrument] 

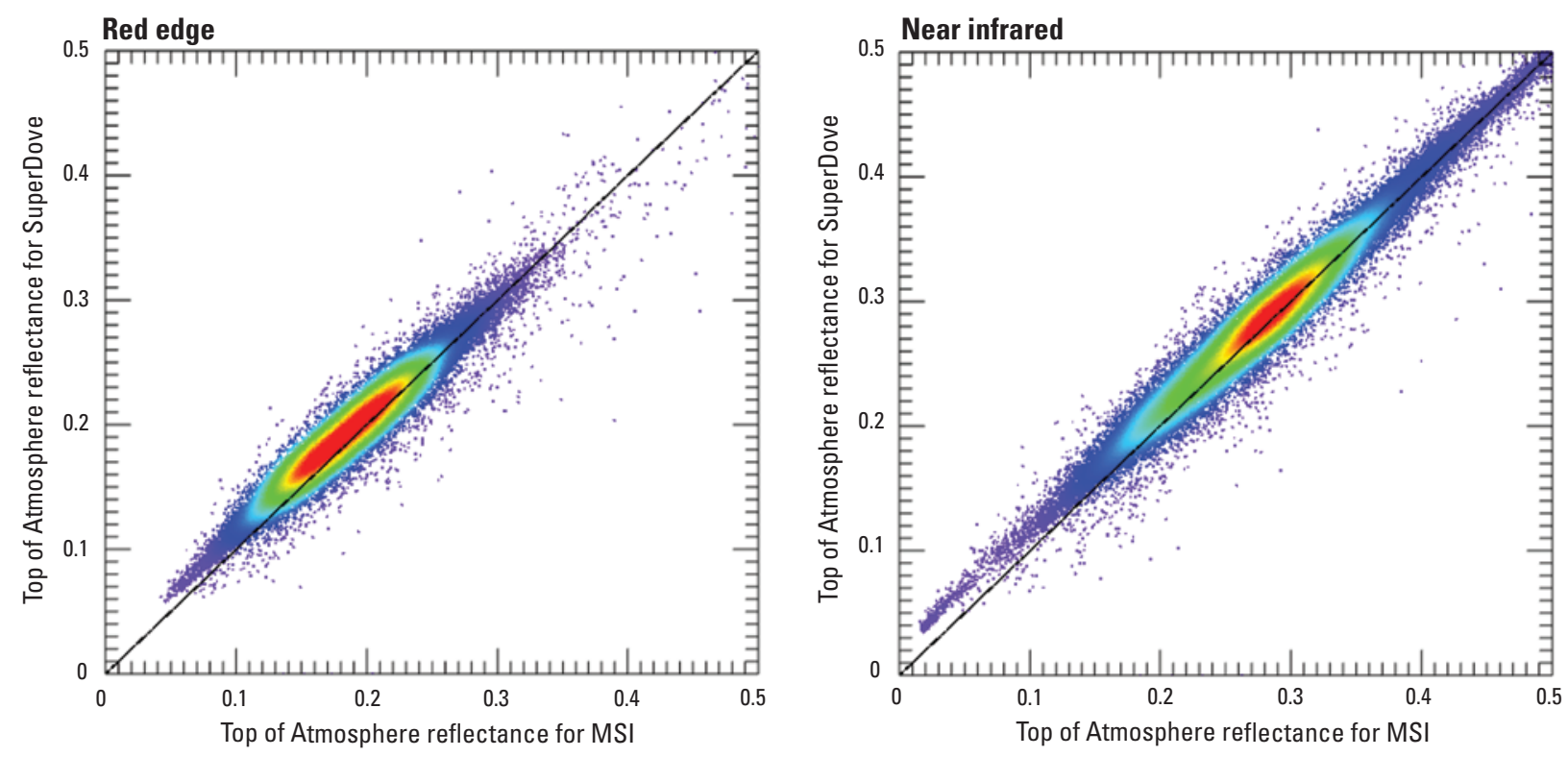

Figure 10. Top of Atmosphere reflectance comparison for Sentinel-2 and Planet's SuperDove 2271 of Scottsdale, Arizona. [MSI, Sentinel-2 Multispectral Instrument]—Continued

\section{Spatial Performance}

For this analysis, edge spread and line spread functions were calculated with resulting full width at half maximum and modulation transfer function at Nyquist frequency analysis outputs, as listed in table 7. The SuperDove image used for the analysis is "20200623_024104_71_2271_3B_AnalyticMS.tif" for Baotou, China (fig. 11), which includes the edge transect bounding box. The results for band 2 (blue) are shown in figures 12 and 13. In figure 12, the raw transects, the middle transect, and the region of the curve that is used for alignment are shown in the upper plot. The lower plot in figure 12 shows the aligned transect curve and the edge spread function. The upper plot in figure 13 shows an edge spread function with the relative edge response and a line spread function with a line segment representing full width at half maximum. The lower plot in figure 13 shows a modulation transfer function up to Nyquist frequency (0.5) and the frequency corresponding to the 50-percent modulation transfer function value.

Table 7. Spatial performance of Planet's SuperDove.

[RER, relative edge response; FWHM, full width at half maximum; MTF, modulation transfer function]

\begin{tabular}{lllll}
\hline & Spatial analysis & RER & FWHM & MTF at Nyquist \\
\hline Band 2-blue & 0.26 & 3.67 pixels & 0.005 \\
Band 4 - green II & 0.25 & 3.70 pixels & 0.008 \\
Band 6-red & 0.26 & 3.59 pixels & 0.005 \\
\hline
\end{tabular}




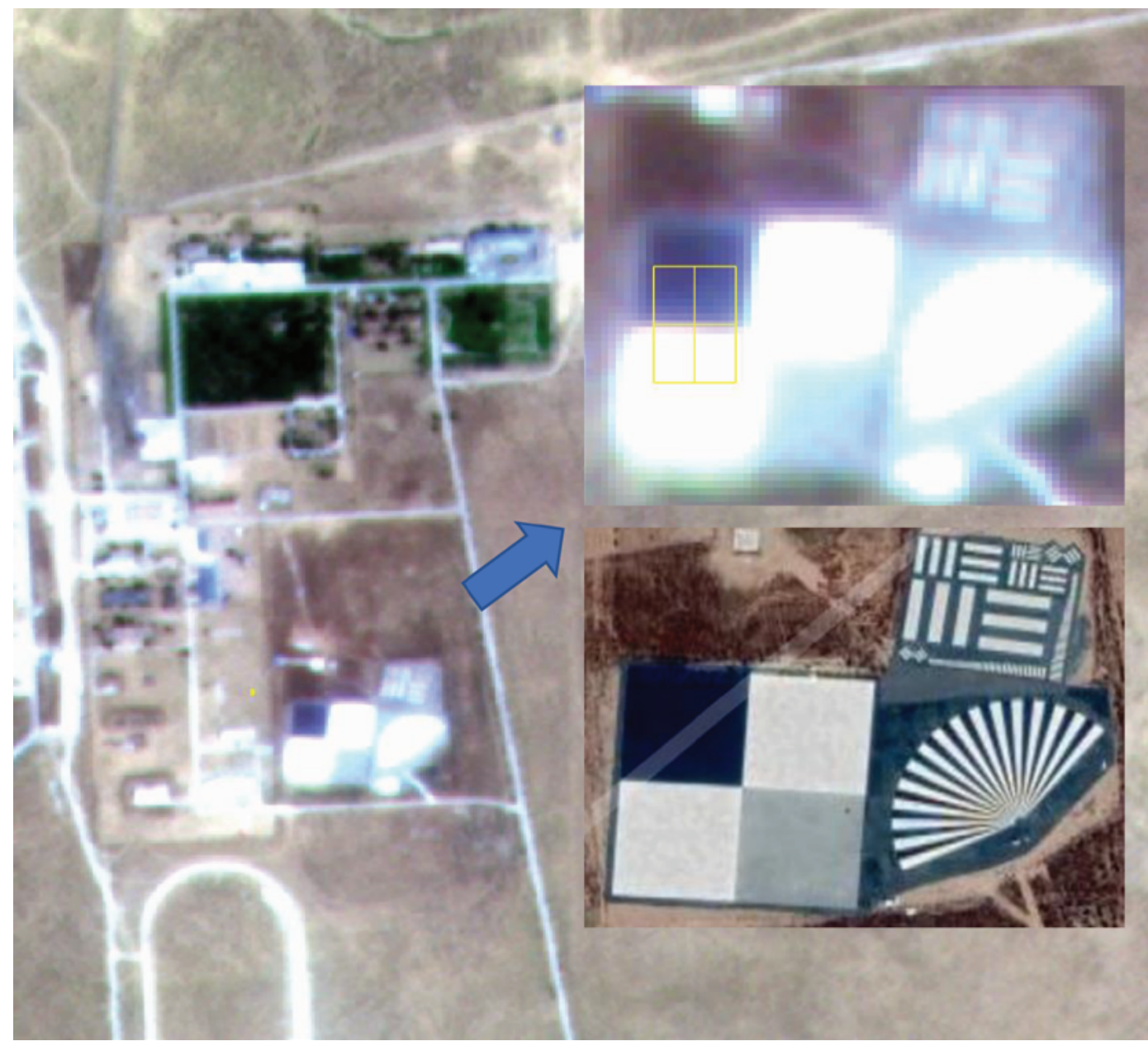

EXPLANATION

Edge transect bounding box

Figure 11. SuperDove image of calibration site at Baotou, China.
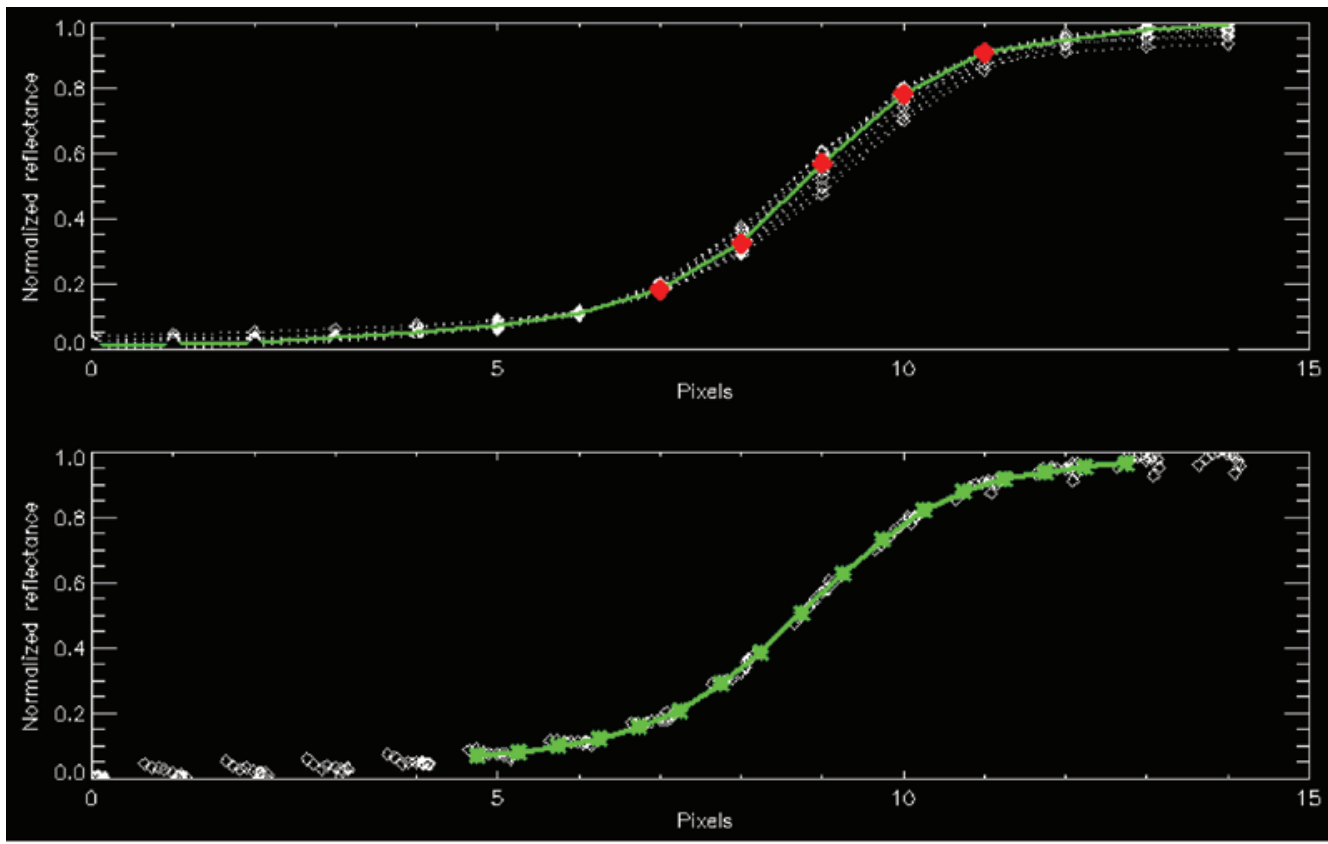

EXPLANATION

Middle transect

Raw transect

Region of the curve used for alignment

EXPLANATION

Edge spread function

\& Aligned transect

Figure 12. Band 2 (blue) raw edge transects (upper) and shifted transects (lower). 

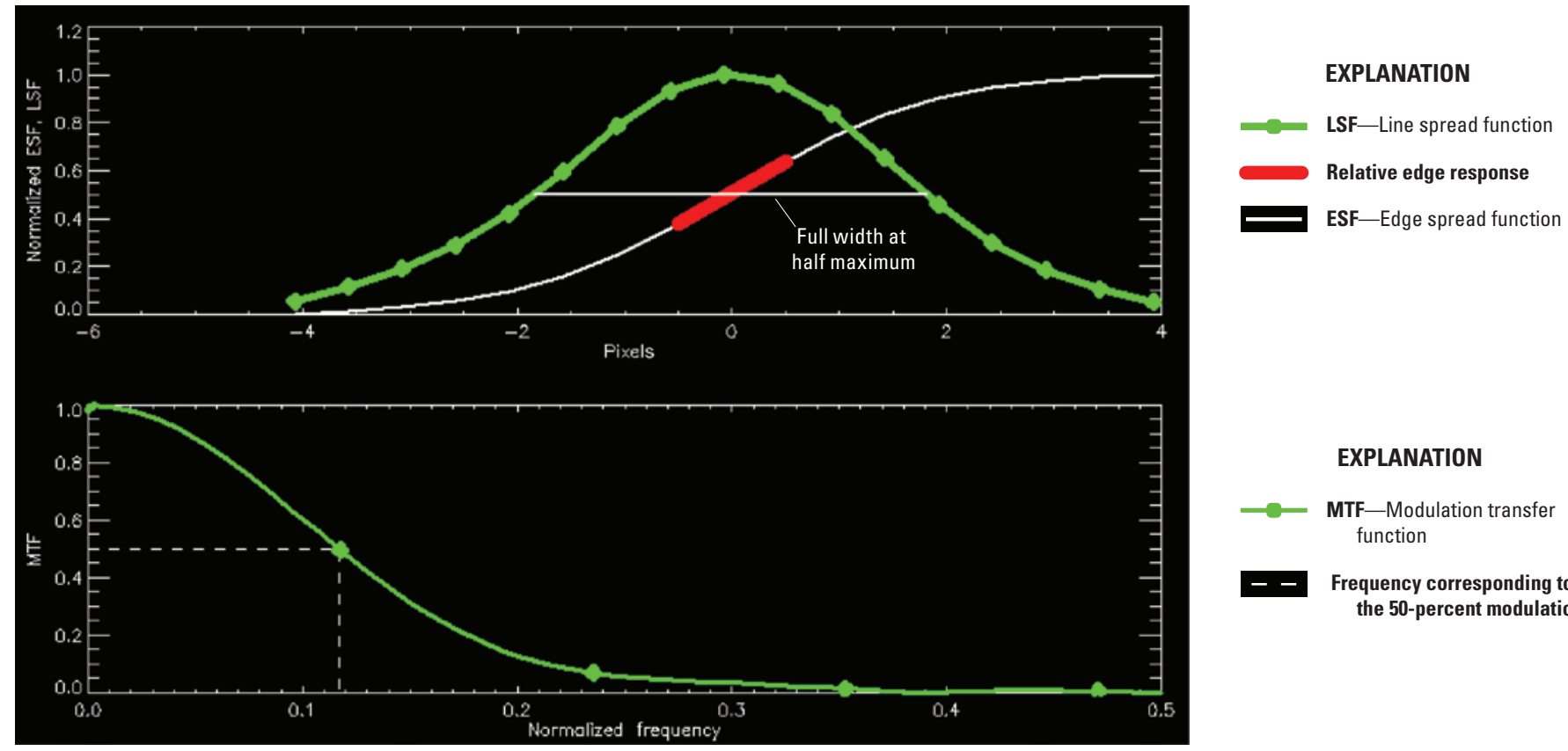

EXPLANATION

MTF-Modulation transfer function

Frequency corresponding to the 50-percent modulation

Figure 13. Band 2 (blue) edge spread function and line spread function (upper) and modulation transfer function (lower). 


\section{Summary and Conclusions}

This report summarizes the sensor performance of Planet's SuperDove system based on the U.S. Geological Survey Earth Resources Observation and Science Cal/Val Center of Excellence (ECCOE) system characterization process. In summary, these analyses indicate that SuperDove has a band-to-band geometric performance in the range of -1.701 meters $(\mathrm{m} ;-0.567$ pixel) to $1.173 \mathrm{~m}(0.391$ pixel $)$ in easting and $-4.950 \mathrm{~m}(-1.650$ pixels) to $6.051 \mathrm{~m} \mathrm{(2.017} \mathrm{pix-}$ els) in northing, an image-to-image geometric performance of $-1.17 \mathrm{~m}$ ( -0.39 pixel) to $23.45 \mathrm{~m}$ (7.82 pixels) in easting and $-10.61 \mathrm{~m}(-3.54$ pixels $)$ to $-4.43 \mathrm{~m}(-1.48$ pixels $)$ in northing offset in comparison to Sentinel-2, a radiometric performance in the range of -0.043 to 0.020 in offset and 0.812 to 1.246 in slope, and a spatial performance in the range of 3.59 to 3.70 pixels for full width at half maximum, with a modulation transfer function at a Nyquist frequency in the range of 0.005 to 0.008 .

In conclusion, the team has completed an ECCOE standardized system characterization of the SuperDove sensing system. Although the team followed characterization procedures that are standardized across the many sensors and sensing systems under evaluation, these procedures are customized to fit the individual sensor, as was done with SuperDove. The team has acquired the data, defined proper testing methodologies, carried out comparative tests against specific references, recorded measurements, completed data analyses, and quantified sensor performance accordingly. The team also endeavored to retain all data, measurements, and methods. This is key to ensure that all data and measurements are archived and accessible and that the performance results are reproducible.

The ECCOE project and associated Joint Agency

Commercial Imagery Evaluation partners are always interested in reviewing sensor and remote sensing application assessments and would like to see and discuss information on similar data and product assessments and reviews. If you would like to discuss system characterization with the U.S. Geological Survey ECCOE and (or) the Joint Agency Commercial Imagery Evaluation team, please email us at eccoe@usgs.gov.

\section{Selected References}

Planet, 2021, Planet: Planet web page, accessed August 2021 at https://www.planet.com/.

Ramaseri Chandra, S.N., Christopherson, J.B., and Casey, K.A., 2020, 2020 Joint Agency Commercial Imagery Evaluation-Remote sensing satellite compendium: U.S. Geological Survey Circular 1468 (ver. 1.1, October 2020), 253 p. [Also available at https://doi.org/10.3133/cir1468.] [Supersedes USGS Circular 1455.]

U.S. Geological Survey, 2020a, EROS CalVal Center of Excellence (ECCOE): U.S. Geological Survey web page, accessed March 2021 at https://www.usgs.gov/calval.

U.S. Geological Survey, 2020b, EROS CalVal Center of Excellence (ECCOE) —JACIE: U.S. Geological Survey web page, accessed November 2021 at https://www.usgs.gov/ core-science-systems/eros/calval/jacie?qt-science_support_ page_related_con=3\#qt-science_support_page_related_con.

U.S. Geological Survey, 2020c, Landsat missions - Glossary and acronyms: U.S. Geological Survey web page, accessed March 2021 at https://www.usgs.gov/core-science-systems/ nli/landsat/glossary-and-acronyms. 

For more information about this publication, contact: Director, USGS Earth Resources Observation and Science Center 47914 252nd Street

Sioux Falls, SD 57198

605-594-6151

For additional information, visit: https://www.usgs.gov/centers/eros

Publishing support provided by the

Rolla Publishing Service Center 


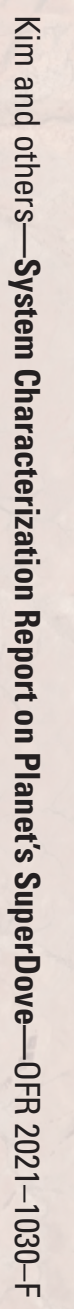

